\title{
Tracheo-oesophageal fistula with anorectal malformation and colonic agenesis:A case report
}

\begin{abstract}
Tracheo-esophageal fistula (TEF) with anorectal malformation (ARM) is a recognized association while colonic agenesis is a rare cause of intestinal obstruction. We present our experience and search of literature in one such case of TEF with high ARM in addition to colonic agenesis in a newborn male child. This combination has not been reported.
\end{abstract}

Keywords: colonic agenesis, tracheo- esophageal fistula, anorectal malformation

\author{
Volume I Issue 7 - 2014
}

Vikrant VK, G Sandlas, S Jayaswal, H Shah Department Of Paediatric Surgery, T.N.M.C \& B.Y.L. Nair Hospital, India

Correspondence: $\mathrm{H}$ Shah, Professor \& HOD, Department Of Paediatric Surgery,T.N.M.C \& B.Y.L. Nair Hospital, Mumbai, Maharashtra-400008, India, Email hemansshah@gmail.com

Received: November 19, 2014 | Published: December I I, 2014
Abbreviations: TEF, tracheo-esophageal fistula; ARM, anorectal malformation; EA, esophageal atresia

\section{Introduction}

Esophageal atresia with Tracheo- esophageal fistula (EA +TEF) is frequently associated with other congenital anomalies. The commonly associated systems are cardiovascular and gastrointestinal, including anorectal malformations. The associated anomalies adversely affect the outcome of the patient. Based on this association Waterson has given a criteria for risk stratification and survival of neonates of $\mathrm{EA}+\mathrm{TEF}^{1}$ (Table 1). There are many case reports of TEF with ARM, but there are no reported cases of TEF with ARM with colonic agenesis.

Table I Waterson Risk Groups

\begin{tabular}{lll} 
Group & Survival (\%) & Waterson Classification \\
\hline A & 100 & $\begin{array}{l}\text { Birth weight }>2500 \mathrm{~g} \text { and otherwise healthy } \\
\text { Birth weight } 2000-2500 \text { gms and well or } \\
\text { higher weight with moderate associated } \\
\text { anomalies }\end{array}$ \\
B & 85 & $\begin{array}{l}\text { Birth weight }<2000 \text { gms or higher with } \\
\text { severe associated cardiac anomalies. }\end{array}$ \\
C & 65 &
\end{tabular}

\section{Case study}

A one day male was admitted with frothing and respiratory distress and absent anal opening. The patient was a full term normal delivery with a birth weight of $2.2 \mathrm{~kg}$ and cried immediately after birth. Antenatal history was not significant. ${ }^{2}$ On examination, the patient had an imperforate anus with poorly developed buttocks. A red rubber catheter could be passed orally only up to $8 \mathrm{~cm}$ from the alveolar margin. Radiographic studies confirmed the findings of EA with TEF (Figure 1). Cross table prone $\mathrm{X}$ ray was indicative of high ARM (Figure 2). Routine laboratories were within normal limits. TEF repair was done via right thoracotomy extrapleural approach. On laparotomy for colostomy, the colon was absent with the small bowel was completely developed up to the ileocaecal junction, and a blind ending caecum with appendix was present (Figure 3). There was no dilatation of the proximal ileum and there was no enterovesical fistula. End caecostomy was performed however the patient succumbed to sepsis on postoperative day $3 .^{3-5}$

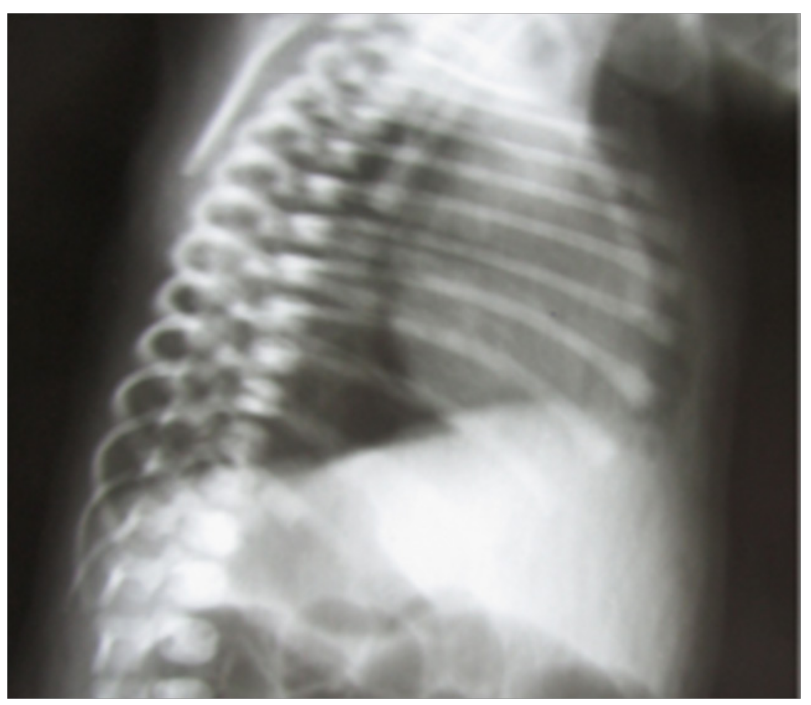

Figure I Radiographic studies:The findings of EA with TEF.

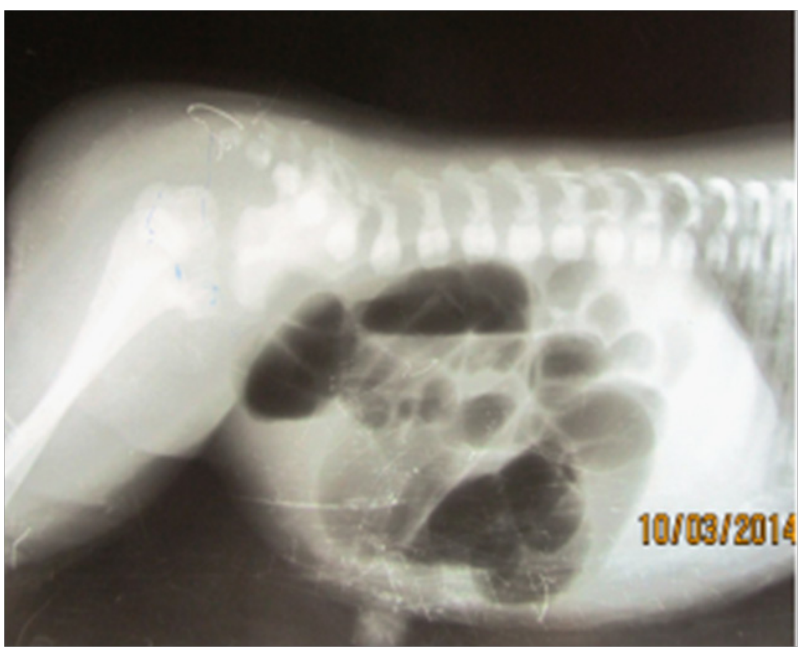

Figure 2 Cross table prone $X$ ray was indicative of high ARM. 


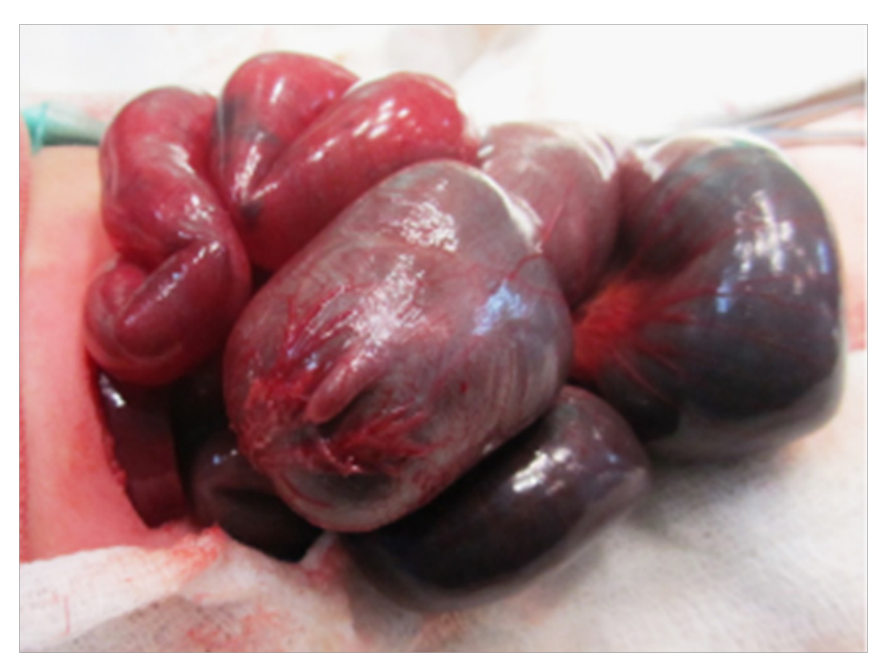

Figure 3 Laparotomy for colostomy, the colon was absent with the small bowel was completely developed up to the ileocaecal junction, and a blind ending caecum with appendix was present.

Table 2 Chiba et al. types of short colon

\section{Agenesis of colon}

2 Short colon without imperforate anus

3 Short colon with imperforate anus (dilated colon)

4 Short colon as a part of exstrophy of bowel and bladder (small and narrow colon)

5 Short colon due to abnormal vessels and the like

\section{Discussion}

$\mathrm{EA}+\mathrm{TEF}$ is associated with many congenital anomalies. The most frequently associated anomalies with $\mathrm{EA} \pm \mathrm{TEF}$ are cardiac $(49 \%)$ and anorectal malformations (15\%) (1-5). There have been many cases of TEF with ARM described. Colonic agenesis is a very rare cause of intestinal obstruction. Congenital short colon has been classified by Chiba et al. (Table 2). In this classification Type 1 is colonic agenesis and there is only one previous case report of colonic agenesis associated with congenital pouch colon and ileovesical fistula. ${ }^{6}$ The early disturbance in organogenesis that results in EA deformities, whatever the exact cause, also affects other organ systems. The exact embryogenesis is unknown. ${ }^{7}$ One theory that is proposed is of aborted hindgut development following obliteration of the inferior mesenteric artery early in fetal life. ${ }^{8}$ Chatterjee proposed that the caecum and the right colon develop normally from the post axial midgut when this portion of the midgut is stimulated by normally developing hindgut. ${ }^{9}$
Thus improper development of the post axial midgut or presplenic gut is due to a primary disorder of the proximal end of the hindgut or post splenic gut. ${ }^{10}$ This case is the first reported case of the combination of EA+TEF with ARM and total colonic agenesis to the best of our knowledge. As in the case this combination of anomalies may be fatal by their inherent nature of the associated malformations.

\section{Acknowledgements}

None.

\section{Conflicts of interest}

None.

\section{Funding}

None.

\section{References}

1. Spitz L. Esophageal Replacement. In: Grosfeld JL, et al. (Eds.), Pediatric Surgery (6th edn), Mosby Elsevier, Philadelphia, London. 2006:10931106.

2. Shaw-Smith C. Oesophageal atresia, tracheo-oesophageal fistula, and the VACTERL association: Review of genetics and epidemiology. J Med Genet. 2006;43(7):545-554.

3. Depaepe A, Dolk H, Lechat MF. The epidemiology of tracheooesophageal fistula and oesophageal atresia in Europe. Arch Dis Child. 1993;68(6):743-748.

4. Chittmittrapap S, Spitz L, Kiely EM, et al. Oesophageal atresia and associated anomalies. Arch Dis Child. 1989;64(3):364-368.

5. Sunita Singh, Ashish Wakhlu, Anand Pandey, et al. Esophageal atresia associated with anorectal malformation: Is the outcome better after surgery in two stages in a limited resources scenario? J Indian Assoc Pediatr Surg. 2012;17(3):107-110.

6. Yurtcu M, Esen HH, Gunel E. Colon agenesis with ileovesical fistula and anorectal malformation. J Pediatr Surg. 2010;45(2):e1-e3.

7. Dickinson SJ. Agenesis of the descending colon with imperforate anus. Correlation with modern concepts of the origin of intestinal atresia. $\mathrm{Am}$ J surg. 1967;113(2):279-281.

8. Chatterjee SK. Anorectal malformations, A surgeons experience. Paediatric surg Int. 2004;20:393-401.

9. Gupta DK, Shilpa Sharma. Congenital pouch colon-Then and now. $J$ Indian Assoc Pediatr Surg. 2007;12(1):1-12. 